\title{
Investigation of residual stress distribution and texture evolution in AA7050 stationary shoulder friction stir welded joints
}

DOI:

10.1016/j.msea.2017.12.019

\section{Document Version}

Accepted author manuscript

Link to publication record in Manchester Research Explorer

Citation for published version (APA):

Sun, T., Tremsin, A. S., Roy, M., Hofmann, M., Prangnell, P., \& Withers, P. (2017). Investigation of residual stress distribution and texture evolution in AA7050 stationary shoulder friction stir welded joints. Materials Science and Engineering A: Structural Materials: Properties, Microstructures and Processing . https://doi.org/10.1016/j.msea.2017.12.019

Published in:

Materials Science and Engineering A: Structural Materials: Properties, Microstructures and Processing

\section{Citing this paper}

Please note that where the full-text provided on Manchester Research Explorer is the Author Accepted Manuscript or Proof version this may differ from the final Published version. If citing, it is advised that you check and use the publisher's definitive version.

\section{General rights}

Copyright and moral rights for the publications made accessible in the Research Explorer are retained by the authors and/or other copyright owners and it is a condition of accessing publications that users recognise and abide by the legal requirements associated with these rights.

\section{Takedown policy}

If you believe that this document breaches copyright please refer to the University of Manchester's Takedown Procedures [http://man.ac.uk/04Y6Bo] or contact uml.scholarlycommunications@manchester.ac.uk providing relevant details, so we can investigate your claim.

\section{OPEN ACCESS}




\section{Author's Accepted Manuscript}

Investigation of residual stress distribution and texture evolution in AA7050 stationary shoulder friction stir welded joints

T. Sun, A.S. Tremsin, M.J. Roy, M. Hofmann, P.B. Prangnell, P.J. Withers

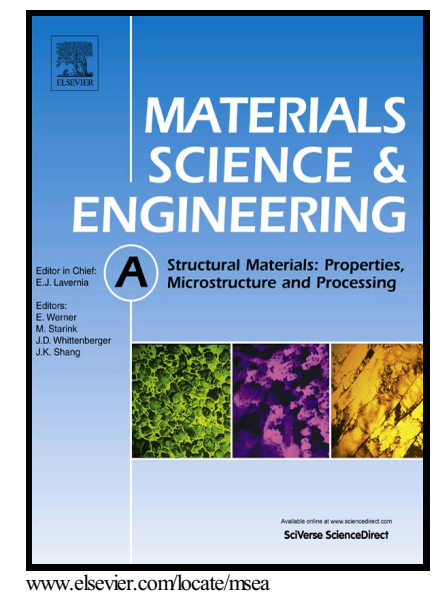

PII: $\quad$ S0921-5093(17)31616-7

DOI: $\quad$ https://doi.org/10.1016/j.msea.2017.12.019

Reference: MSA35861

To appear in: $\quad$ Materials Science \& Engineering $A$

Received date: 8 October 2017

Accepted date: 7 December 2017

Cite this article as: T. Sun, A.S. Tremsin, M.J. Roy, M. Hofmann, P.B. Prangnell and P.J. Withers, Investigation of residual stress distribution and texture evolution in AA7050 stationary shoulder friction stir welded joints, Materials Science \& Engineering A, https://doi.org/10.1016/j.msea.2017.12.019

This is a PDF file of an unedited manuscript that has been accepted for publication. As a service to our customers we are providing this early version of the manuscript. The manuscript will undergo copyediting, typesetting, and review of the resulting galley proof before it is published in its final citable form. Please note that during the production process errors may be discovered which could affect the content, and all legal disclaimers that apply to the journal pertain. 
Investigation of residual stress distribution and texture evolution in AA7050 stationary shoulder friction stir welded joints

T. Sun ${ }^{1 *}$, A.S. Tremsin ${ }^{2}$, M. J. Roy ${ }^{3}$, M. Hofmann ${ }^{4}$, P.B. Prangnell ${ }^{1}$, P.J. Withers ${ }^{1}$

${ }^{1}$ School of Materials, the University of Manchester, Manchester M13 9PL, UK

${ }^{2}$ Space Sciences Laboratory, University of California at Berkeley, Berkeley, CA, USA

${ }^{3}$ School of Mechanical, Aerospace and Civil Engineering, the University of Manchester, Manchester M13 9PL, UK

${ }^{4}$ FRM II TU Munich, Lichtenbergstrasse 1, D-85747 Garching, Germany

*Corresponding author. Tel: +447707044541 e-mail: tianzhu.sun@postgrad.manchester.ac.uk 


\title{
ACCEPTED MANUSCRIPT
}

\begin{abstract}
A study of the residual stress distribution and texture evolution in stationary shoulder friction stir welded (SSFSW) AA7050 plate through non-destructive energy-resolved neutron imaging (NI), monochromatic neutron diffraction (ND) and destructive contour method (CM) is described in this paper. The presence of Bragg edges in the neutron transmission spectra are shown to be effective in determining the longitudinal residual stress and compare well with results obtained by ND and CM. The texture in the weld zone and base metal has been mapped by contrast in the narrow-energy transmission image combined with an analysis of the Bragg edges in the transmission spectra at each pixel showing agreement with the results obtained by electron backscatter diffraction (EBSD) mapping. The ND results were complicated by plastic anisotropy effects in the rolled plate which meant that different reference stress-free lattice spacings were required at each point in the 3 principal directions for this material. NI and CM were unaffected by texture effects in determining residual stress. Compared to conventional techniques, NI is shown to be an effective way of quantifying both texture and residual stress in one shot.
\end{abstract}

Keywords: SSFSW, AA7050, neutron transmission, neutron diffraction, contour method 


\section{ACCEPTED MANUSCRIPT}

\section{Introduction}

Stationary shoulder friction stir welding (SSFSW) is a relatively new variant of friction stir welding (FSW). It differs from conventional FSW in that the shoulder is distinct form the pin and does not rotate. This confers a more uniform through thickness thermal field and potentially, superior welds [1]. Previous studies have found that the use of SSFSW for joining aluminium alloys leads to a better surface finish and more uniform through-thickness properties. This includes a smaller nugget grain size and higher hardness, as compared to FSW [2-5]. Furthermore, a narrower thermal field is possible due to a lower and more localised heat input [6]. Although there have been numerous studies demonstrating the potential of the SSFSW process, there have been few studies [4] looking at the residual stress distribution which is an important factor when determining the service life of welded structural component [7].

Neutron diffraction (ND) is now a well-accepted tool for the non-destructive evaluation of residual stress in much thicker section components than can be accessed by laboratory X-ray diffraction [8]. With this technique, residual strains are measured by tracking the difference in the lattice spacing between the specimen and a stress-free reference. Numerous neutron diffraction studies of residual stress development in FSW plate have been reported often validated by complementary techniques. Prime et al. [9] investigated the residual stress in AA2024-AA7050 thick dissimilar weld by both ND and the contour method (CM) and results were in agreement in the weld region, but conflicted in the base metal (BM). Recently, an alternative technique was developed which determines residual strain by detecting the neutrons that pass straight through the sample to give a transmission spectra $[10,11]$. Compared to the conventional neutron diffraction technique, which measures strain components in a three dimensional gauge volume, typically $1 \mathrm{~mm}^{3}$ or larger, neutron transmission imaging (NI) allows mapping strains in two (in-plane) dimensions with a lateral spatial resolution of better than $100 \mu \mathrm{m}$ [12]. One advantage is that with an area detector it is possible to image the strain distribution in a given area at one time rather than having to scan a gauge volume through the sample[13]. The limitation of NI is that it can only measure the strain component parallel to the incident neutron beam and because there is no discrimination along the neutron path length, it represents a through-thickness average strain [11]. Provided the weld coupon is long enough [14] for the stress to be little affected by relaxation towards the entry and exit surfaces this consideration may not be an issue because the longitudinal stress does not vary significantly along the steady state region of the weld length [15]. 


\section{ACCEPTED MANUSCRIPT}

Tremsin et al. [16] characterised the microstructural features and internal residual strain in dissimilar metal welds by NI, and demonstrated the potential for elemental composition assessment within the weld, besides residual strain reconstruction. Tremsin et al. [17] also investigated the strain distribution of different components under load and proposed the potential application of in-situ NI.

As described by Withers et al. [18], the determination of a stress-free lattice spacing $\left(\mathrm{d}_{0}\right)$ is mandatory in diffraction-based weld residual stress measurements because the initial state of the workpiece heavily influences the stress-free lattice parameter, especially for aluminium alloys. Barrett et al. [19] demonstrated that for heat-treatable aluminium alloys $\mathrm{d}_{0}$ is extremely sensitive to the change in the solute content, for example 1 at. \% increase of $\mathrm{Mg}$ in solution can lead to around $3.75 \times 10^{-3} \AA$ (equivalent to a strain of $927 \times 10^{-6}$ ) change in the lattice spacing of the aluminum matrix while 1 at. \% increase in $\mathrm{Zn}$ could result in the decrease of lattice spacing by $6.6 \times 10-4 \AA$ (or $165 \times 10^{-6}$ ). In the case of aluminium alloy FSW joints, the solute content is closely related to the precipitate evolution which is chiefly governed by the thermal process [20]. Dumont et al. [21] studied the volume fraction of precipitates in the AA7449 FSW plate and found that for the T79 temper, there was a gradual decrease in the HAZ due to the coarsening and/or dissolution of precipitates. Furthermore, they found that in the weld nugget (WN) nearly all the precipitates have dissolved into the matrix due to the high temperatures generated during welding and that these re-precipitate during subsequent natural ageing. Since the precipitate volume fraction varies with the position across the weld, the variation in $\mathrm{d}_{0}$ needs to be measured across the weld. The most common means of doing this is to create a stress-free (comb) sample cut from a an identical weld for which the dimensions are too fine to maintain significant residual stress [18]. While such samples may retain some intergranular stress, this intergranular stress is also present in the uncut weld and will be canceled out when calculating the change in lattice spacing leaving only the macro-stress related strain [22].

In the current work, we investigate the reliability of NI for residual stress mapping in SSFSW through a comparison with measurements made by ND and CM. One of the advantages of NI is that it also provides a measure of the texture changes across the weld and so this is compared with electron back scattered diffraction (EBSD) texture measurements. 


\section{ACCEPTED MANUSCRIPT}

\section{Experimental details}

\subsection{Welding procedure}

The $6.3 \mathrm{~mm}$ thick, hot rolled AA7050 plates were welded with a SSFSW tool having $18 \mathrm{~mm}$ diameter shoulder and a $5.9 \mathrm{~mm}$ long conical threaded tri-flat pin, with the root and tip diameters of $6.2 \mathrm{~mm}$ and $4 \mathrm{~mm}$. Detailed descriptions of the welding procedures, including the welding configuration, torque, input power and thermal history have been documented elsewhere [4, 5]. The matrix of welding parameters and corresponding residual stress measurement technique is shown in Table 1.

\begin{tabular}{lccccc}
\hline Designation & $\begin{array}{c}\text { Rotation speed } \\
(\mathrm{rpm})\end{array}$ & $\begin{array}{c}\text { Travel Speed } \\
(\mathrm{mm} / \mathrm{min})\end{array}$ & $\begin{array}{c}\text { Welding } \\
\text { Power }(\mathrm{W})\end{array}$ & $\begin{array}{c}\text { Line } \\
\text { energy }(\mathrm{J} / \mathrm{mm})\end{array}$ & $\begin{array}{c}\text { Measurement } \\
\text { Techniques }\end{array}$ \\
\hline SS1500/100 & 1500 & 100 & 1330 & 796 & CM, NI \\
SS1500/200 & 1500 & 200 & 1550 & 464 & CM, NI \\
SS1500/400 & 1500 & 400 & 2360 & 355 & CM, NI \\
SS1300/200 & 1300 & 200 & 1750 & 526 & CM, ND \\
SS1700/200 & 1700 & 200 & 1610 & 482 & CM, ND \\
\hline
\end{tabular}

Table 1 Matrix of SSFSW parameters used in this paper and applied residual stress measurement techniques for each condition.

\subsection{Neutron diffraction}

Three perpendicular strains along the longitudinal (LD), transverse (TD) and normal (ND) directions across the weld at the mid-length (see Fig.1(a)) were determined by neutron diffraction at FRM II, using the neutron diffractometer STRESS-SPEC [23]. A monochromatic neutron beam with the wavelength of $1.69 \AA$ from $\mathrm{Si}$ (400) was selected for the strain scanning, which means the $\mathrm{Al}$ (311) Bragg reflection occurs at a scattering angle of $2 \theta \approx 88^{\circ}$ giving an essentially cuboidal gauge volume. The Al (311) peak position was chosen because it is weakly affected by intergranular stress and shows good linearity of strain under uniaxial loading even beyond the yield stress [8]. Gauge volumes were $2(\mathrm{LD}) \times$ $2(\mathrm{TD}) \times 2(\mathrm{ND}) \mathrm{mm}^{3}$ for the longitudinal strain measurement and $10(\mathrm{LD}) \times 2(\mathrm{TD}) \times 2(\mathrm{ND})$ $\mathrm{mm}^{3}$ for both transverse and normal strain measurements. The experimental set-up is shown in Fig. 2. To determine the stress-free lattice spacing, $\mathrm{d}_{0}$, as a function of position across the weld, $\mathrm{a} \mathrm{d}_{0}$ 'comb' sample having teeth $4.5(\mathrm{LD}) \times 3(\mathrm{TD}) \times 1.7(\mathrm{ND}) \mathrm{mm}^{3}$ was machined using electro-discharge machining (EDM) from an identically welded plate at the mid-length and 


\section{ACCEPTED MANUSCRIPT}

mid-thickness as shown in Fig. 1(c). The gauge volume for $\mathrm{d}_{0}$ determination was $4(\mathrm{LD}) \times$ $2(\mathrm{TD}) \times 1.5$ (ND) $\mathrm{mm}^{3}$ in all three principal directions. It should be noted that to avoid the deviation arising from the different level of natural ageing and so that the precipitate behavior between the weld and stress-free come sample, both of them have experienced natural ageing for 6 months. The raw diffraction data were analysed using StressTextureCalculator (STeCa) software to extract the scattering angle $2 \theta$ of diffraction peaks. Residual strain $\varepsilon$ was calculated using the equation:

$$
\varepsilon=\frac{d-d_{0}}{d_{0}}=\frac{\sin \theta}{\sin \theta_{0}}-1
$$

Where $\mathrm{d}$ is the $\mathrm{Al}$ (311) lattice spacing of the weld plate, $\theta$ is the diffraction angle of the weld sample and $\theta_{0}$ is the diffraction angle of stress free comb sample. Residual stress $\sigma$ is then calculated using the triaxial form of Hooke's Law:

$$
\sigma_{i i}=\frac{E_{311}}{1+v_{311}}\left[\varepsilon_{i i}+\frac{v_{311}}{1-2 v_{311}}\left(\varepsilon_{x x}+\varepsilon_{y y}+\varepsilon_{z z}\right)\right]
$$

Where $\mathrm{i}=\mathrm{x}, \mathrm{y}, \mathrm{z}$ correspond to TD, ND and $\mathrm{LD}$, and $E_{311}=70.2 \mathrm{GPa}, v_{311}=0.35$ are the $\mathrm{Al}$ (311) specific elastic modulus and Poisson's ratio [8], $\varepsilon_{i i}$ is the strain in three perpendicular directions determined by the previous equation.

(a)

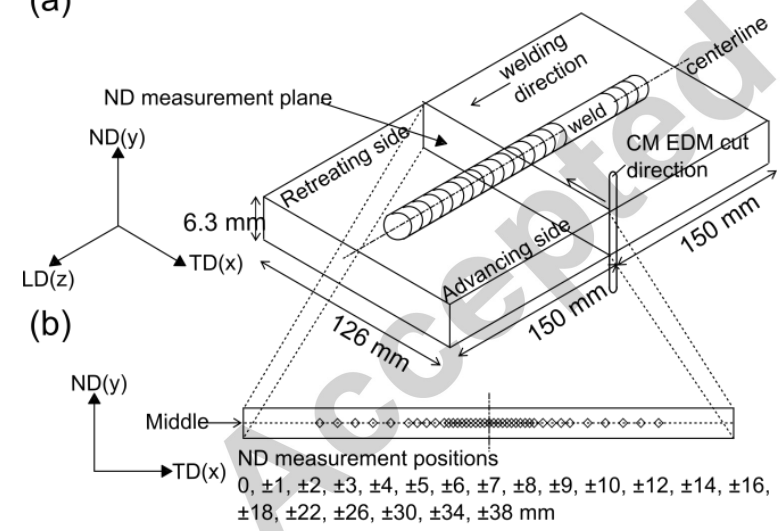

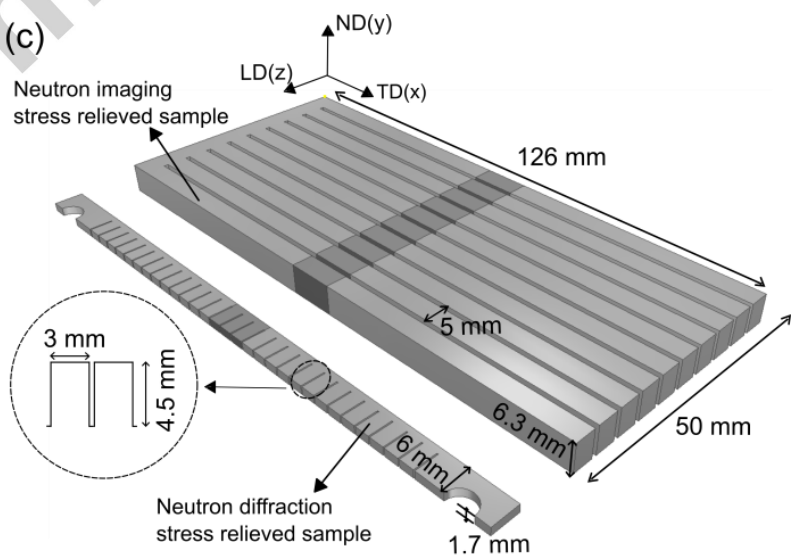

Fig. 1 Schematic of (a) residual stress determined positions by Neutron diffraction and contour method, (b) spatially resolved neutron diffraction measurement positions across the centreline of the weld plate, (c) mechanically stress-free reference samples used for the neutron diffraction and neutron imaging. 


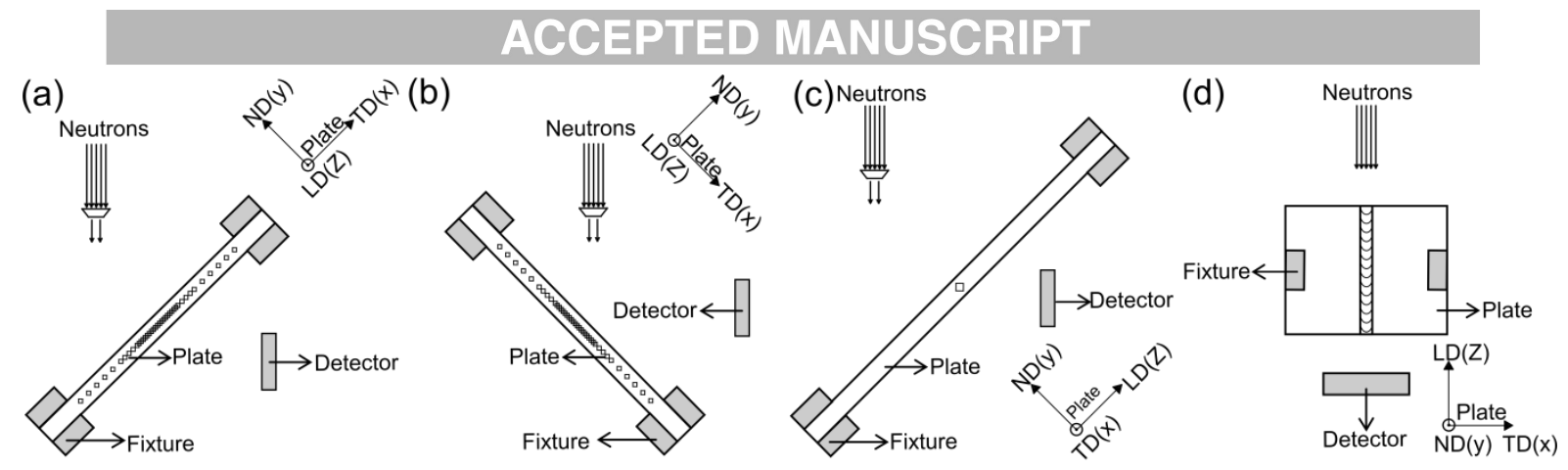

Fig. 2 Top views of weld plate set-ups for neutron diffraction measurement in (a) TD, (b) ND, (c) LD and (d) neutron imaging measurement in LD. Note that weld plate is not drawn to scale.

\subsection{Neutron imaging}

Energy-resolved neutron transmission imaging was performed at the Noboru pulsed beamline facility at the Japan Proton Accelerator Research Complex [24]. The weld samples were placed in the direct neutron beam in front of a neutron counting detector as shown in Fig. 2(d) [25], which measured the time (relative to the source trigger) and position of each registered neutron. The distance between the detector and the spallation neutron source was $14.25 \mathrm{~m}$ and active area of the detector is $28 \times 28 \mathrm{~mm}^{2}$. The energy of each neutron was reconstructed from its time of flight, as described in detail in references $[12,16,17]$. Recent development of this detection technology allows simultaneous detection of $>250000$ transmission spectra, each with $55 \times 55 \mu \mathrm{m}^{2}$ pixels. At the same time, a broad range of neutron wavelengths $(0.1-8$ $\AA$ A) was measured simultaneously, with several thousands of narrow-energy images saved per each data set $[13,16,17]$. Two pairs of samples (the weld and its stress-free counterpart) were measured simultaneously, with the integration time 2-3 hours per sample set. The weld was $80 \mathrm{~mm}$ in length and the stress-free specimen had a length of $50 \mathrm{~mm}$, both sectioned from the original weld at the steady-state region (more than $60 \mathrm{~mm}$ away from the weld start/end). A schematic of the stress-free specimen is shown in Fig. 1(c) .The longitudinal residual stress in the stress-free specimen was released by several parallel cuts with the spacing of $5 \mathrm{~mm}$ and each cut was through the whole thickness across the weld leaving $5 \mathrm{~mm}$ remnant at one side to assist the specimen positioning during the measurement. All transmission data was normalized by the data measured with no sample in the beam ('open beam' normalization) to eliminate the intrinsic features of the beam and detector nonuniformities. 


\subsection{Contour method}

Residual stress measurement using the contour method was carried out as a destructive method for direct comparison with the non-destructive neutron techniques. In this study, contour method was only used on the TD-ND cross section to determine the longitudinal residual stress $\left(\sigma_{z z}(x, y)\right)$. An EDM cut was performed with the sample in a fixture to constrain sample movement during cutting and operated from the advancing side (AS) to the retreating side (RS) before the making of comb sample on the alternative weld plate as described in the previous section. Further details regarding the contour method measurement protocol and measurement practice are available elsewhere [4].

\subsection{Microstructure characterisation}

Texture evolution was characterised on the TD-ND cross-section at mid-length by EBSD. The specimen was prepared following the standard metallographic procedures and then lightly electro-polished in $20 \%$ perchloric acid in ethanol $\left(-15^{\circ} \mathrm{C}, 20 \mathrm{~V}\right)$ to produce a strain free surface. Orientation maps were collected with Aztec acquisition software. Large areas maps of $\sim 11.5 \times 6.3 \mathrm{~mm}$ in the weld centre and $0.6 \times 6.3 \mathrm{~mm}$ in the BM, with a $3 \mu \mathrm{m}$ step size were generated. These maps were used to obtain the texture data and provide comparative macro-view of the weld zone and base material.

\section{Results}

\subsection{Residual stress distributions measured by neutron diffraction}

Fig. 3 shows the variation across the plate at the mid-thickness of the residual stress components oriented with the LD, TD and RD directions, as determined by neutron diffraction in the SS1700/200 and SS1300/200 weld plates. It can be seen that there is a significant level of tensile stress (up to $170 \mathrm{MPa}$ ) concentrated near the weld centre in the LD $\left(\sigma_{z z}(\mathrm{x})\right)$ compared with a low level compressive stress in the TD $\left(\sigma_{x x}(\mathrm{x})\right)$ and ND $\left(\sigma_{y y}(\mathrm{x})\right)$ directions. The longitudinal residual stress shows a characteristic ' $M$ ' shaped profile, which is comparable to previous studies on the FSW of 7xxx series aluminium alloy $[14,26]$ and the development of this profile feature has been discussed by Richards et .al. [27] and Sun et al. [4]. Additionally, it has been proposed by Sun et al. [4] on the basis of neutron diffraction measurements that in the SSFSW residual stress is mainly determined by the travel speed and less strongly influenced by the rotation rate. The asymmetrical residual stress distribution is caused by the asymmetry of the welding process. For the LD residual stress, there is a higher peak residual stress on the advancing side (AS) compared with retreating side (RS). Wade 


\section{ACCEPTED MANUSCRIPT}

and Reynolds [28] attributed this to the higher peak temperature on the AS due to the greater level of thermomechanical effect and strain rate.

(a)

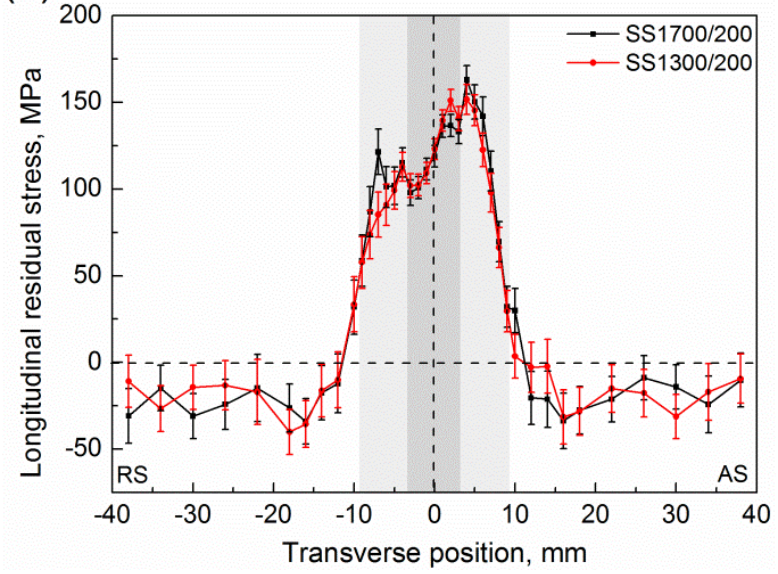

(c)

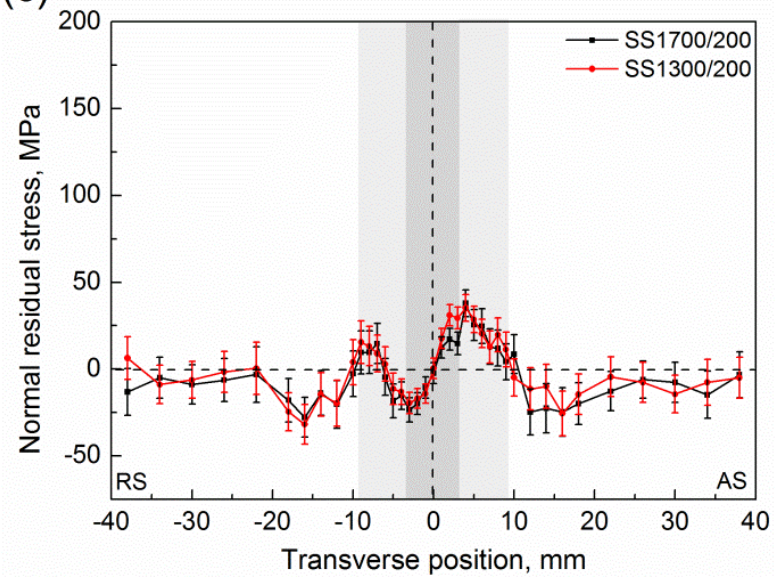

(b)

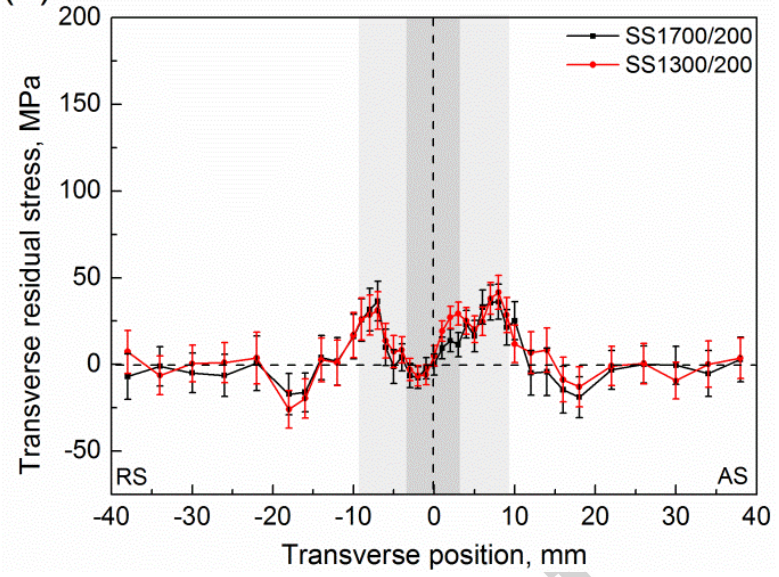

Fig. 3 Residual stress distributions determined by neutron diffraction at STRESS-SPEC, FRM II for the stresses components (a) $\sigma_{z z}(x)$, (b) $\sigma_{x x}(x)$ and (c) $\sigma_{y y}(x)$, at mid-thickness of the weld plate for SS1700/200 and SS1300/200.

\subsection{Residual stress distribution measured by neutron imaging}

Representative transmission spectra are shown in Fig. 4. The sharp steps in transmission, known as Bragg edges, arising from neutrons removed from the transmitted beam by Bragg diffraction in polycrystalline materials, are used to determine the crystal lattice parameter [17]. The strain resolution of the strain map is mainly influenced by the width of the neutron pulse, which is $\sim 50 \mu$ s here and corresponds to a strain of $3000 \times 10^{-6}$. This can be improved up to $\sim 100 \times 10^{-6}$ by fitting the spectra using the function shown below [12]. 


$$
\left.T(\lambda)\right|_{\lambda_{0}, \sigma, \tau, C_{1}, C_{2}}=C_{1}+C_{2}\left[\operatorname{erfc}\left(\frac{\lambda_{e}-\lambda}{\sqrt{2} \sigma}\right)-\exp \left(\frac{\lambda_{e}-\lambda}{\tau}+\frac{\sigma^{2}}{2 \tau^{2}}\right) \times \operatorname{erfc}\left(\frac{\lambda_{e}-\lambda}{\sqrt{2} \sigma}+\frac{\sigma}{\sqrt{2} \tau}\right)\right]
$$

where $\lambda_{e}$ is the wavelength of the Bragg edge, $\sigma, \tau, \mathrm{C}_{1}$ and $\mathrm{C}_{2}$ are the width, asymmetry, offset and height of the edge, respectively. Due to the apparently higher transmission edge intensity, data fitting would be focused on the data set of $\{111\}$ edge and the fit values of parameters $\sigma, \tau, C_{1}$ and $C_{2}$ for the $\{111\}$ edge were $0.00471,0.00807,0.3597$ and 0.33656 , respectively. The edge position $\lambda$ of defined by least squares fitting and converted into lattice spacing with the relationship:

$$
\lambda=2 d_{111}(4)
$$

Lattice spacing were determined in both stress-free sample $\left(d_{0,111}\right)$ and the weld plate $\left(d_{111}\right)$ and local $d_{0,111}(\mathrm{x}, \mathrm{y})$ was then applied to determine the stress at the same $(\mathrm{x}, \mathrm{y})$ position in the weld plate with the $\mathrm{Al}$ (111) specific elastic modulus, $E_{111}=73.4$ [8]. The longitudinal residual stress maps obtained by NI in Fig. 5(a) show large tensile stresses in the weld centre and the tensile zone shrinks somewhat from the top to the bottom surface due to the shape of the heat source. For the higher travel speed, the tensile region is reduced in the size but increased in magnitude. These findings are in excellent agreement with the residual stress maps in Fig. 5(b) determined by the contour method and demonstrate the great potential of neutron imaging for the residual stress determination in the weldments with high resolution.

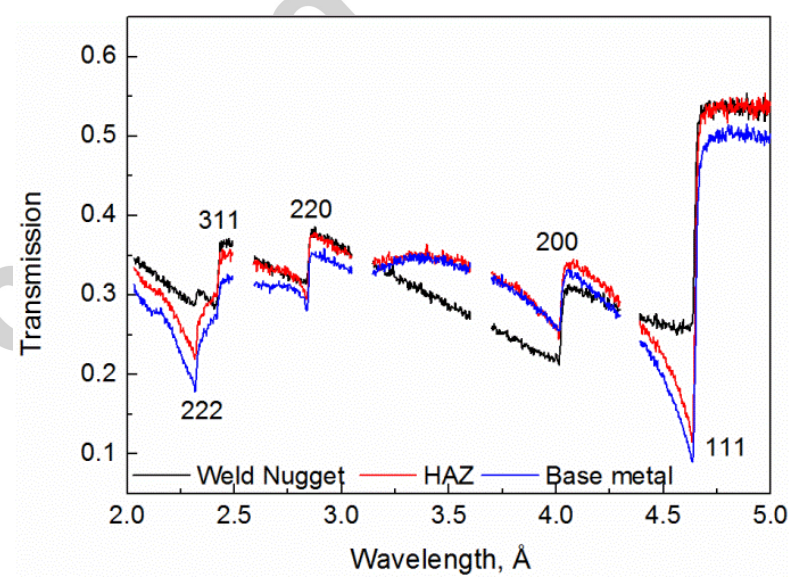

Fig. 4 Typical neutron transmission spectra measured at different weld zones in SS1500/200. 
(a)

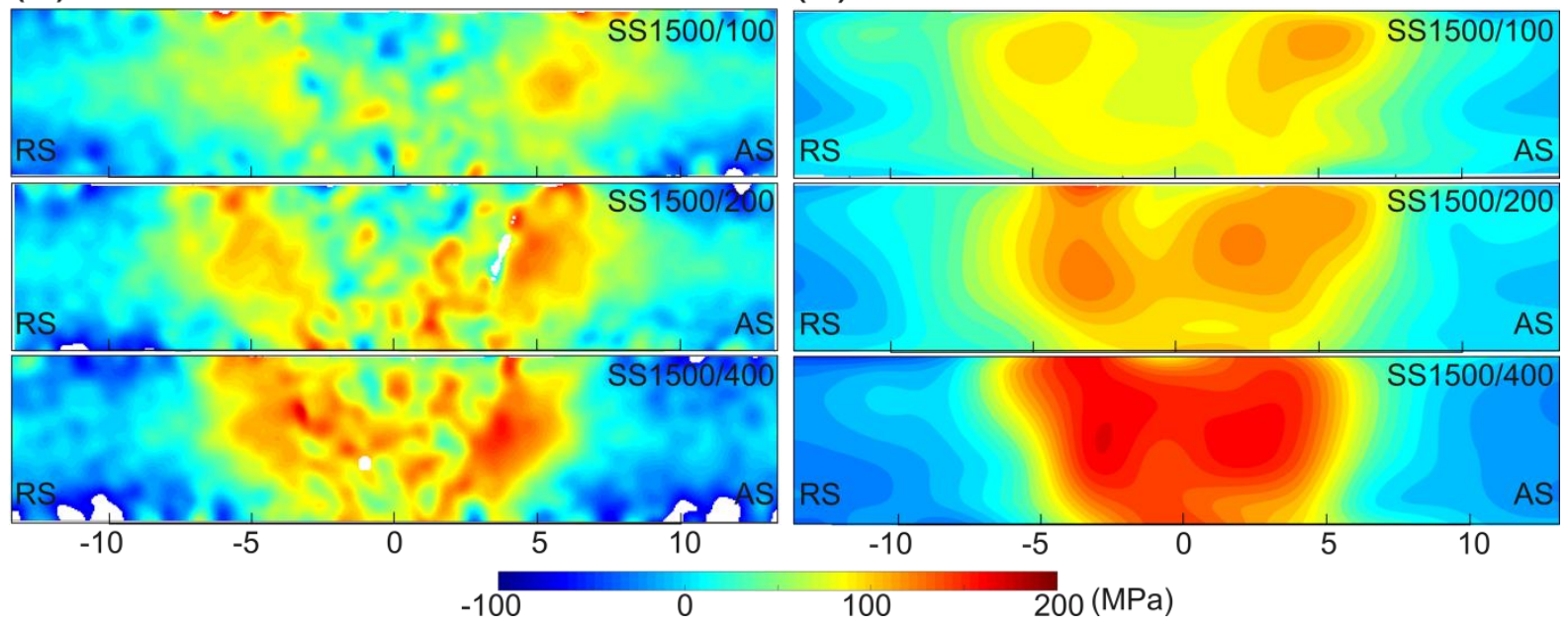

Fig. 5 Reconstructed longitudinal residual stress contour maps for SSFSWs (the welding parameters are shown on each map) determined by (a) neutron imaging through (i.e. averaged over) $80 \mathrm{~mm}$ length of the weld and (b) from a mid-weld length cross-section by the contour method.

\section{Discussion}

\subsection{Changes in the unstrained lattice parameter}

In the case of a heat-treatable aluminum welded plate, there is a significant variation in the thermal history experienced across the weld zone, which results in an evolution of composition and microstructure change across the weld. This gives rise to a significant variation in do across the $(\mathrm{x}, \mathrm{y})$ cross section. In the present study, stress-free samples from an additional weld made with the same welding parameters were employed to determine $\mathrm{d}_{0}(\mathrm{x}$, y). Since the position the teeth are slightly different from the stress measurement positions, the raw data was fitted and interpolated over all $(x, y)$. The variations of $d_{0}$ in all three principal directions are shown in Fig. 6 . It can be seen that $\mathrm{d}_{0}$ varies significantly from the base material (BM) to the weld nugget (WN) for all three directions, with a maximum value near the weld centre and a sharp decrease in HAZ. While the 3 directions are in excellent agreement in the $\mathrm{WN}$, the $\mathrm{d} 0$ in the $\mathrm{BM}$ differs dramatically in the three principal directions which equates to a 'stress free strain' of $\sim 1650 \times 10^{-6}$ (which if unaccounted for would appear to represent a stress of around $120 \mathrm{MPa}$ ). This is probably because of anisotropic intergranular strains (plastic anisotropy between the hkl peaks) resulting from the rolling route during the production of the plate. These are evident in the base material but absent in the weld nugget due to the random-distributed recrystallized grains. Pang et al. [29] investigated the intergranular strains in the rolled AA7050 plate and proposed that the 


\section{ACCEPTED MANUSCRIPT}

compressive intergranular strain determined from $\mathrm{Al}$ (311) peak is asymmetrical along three principal directions and the largest amount of deformation was found along RD (TD) while minimum along LD. This agrees with our observation that the $\mathrm{d}_{0}$ is significantly higher in the LD followed by the ND and the LD as shown in Fig. 6. Additionally, Ganguly et al. [22] found that the difference in the lattice spacing obtained from the refinement of individual peaks of the diffraction spectra can be omitted by the refinement of the entire diffraction spectra. This demonstrates the necessity of measuring $\mathrm{d}_{0}$ in all three directions for deformed plate.

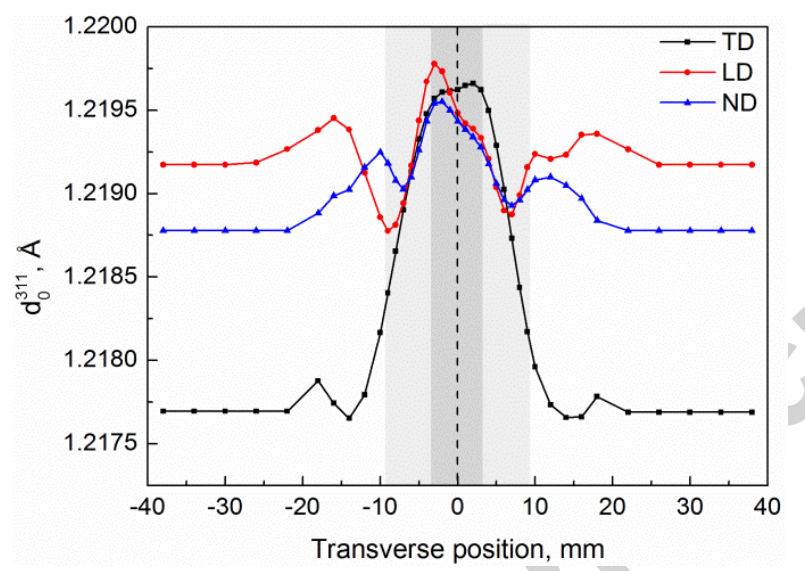

Fig. 6 Stress-free lattice spacing, $\mathrm{d}_{0}$ distributions along three principal directions, fitted by $\mathrm{Al}$ (311) peak in the comb sample produced from SS1700/200 weld plate.

Besides the necessity of $\mathrm{d}_{0}$ measurement in all three directions, it is also essential to determine the $d_{0}$ variation with adequate resolution from HAZ to WN due to the sharp change in the transition zone as shown in Fig. 6. Though the hardness in heat-treatable aluminium alloys is dominated by the size and type of precipitation and $\mathrm{d}_{0}$ is influenced by the amount of alloy elements remaining in the solution [30], there is still a correlation between the hardness and $\mathrm{d}_{0}$ distribution as shown in Fig.7. Hence, variation in hardness could be a good indicator for the $\mathrm{d}_{0}$ measurement before the neutron diffraction experiment in terms of the extent and density. An upper bound for the change in the lattice spacing can be estimated by assuming that all the solute $\mathrm{Mg}$ has been precipitated with $\mathrm{Zn}$ to form $\mathrm{MgZn}_{2}$. On this basis there should be an apparent strain around $1900 \times 10^{-6}$ considering the chemical composition of AA7050 [31]. Sha and Cerezo [32] found that there was around $600 \times 10^{-6}$ strain shift during ageing at $120^{\circ} \mathrm{C}$ from the solution-treated condition. The variation determined in the current study $\left(1640 \times 10^{-6}\right.$ in TD) is between these two values and thus in line with what would be expected. It is assumed that the difference from age-hardening in the strain shift probably 


\section{ACCEPTED MANUSCRIPT}

results from the thermomechanical work that leads to a greater evolution of precipitate distribution than that found by isothermal ageing at low temperature [33].

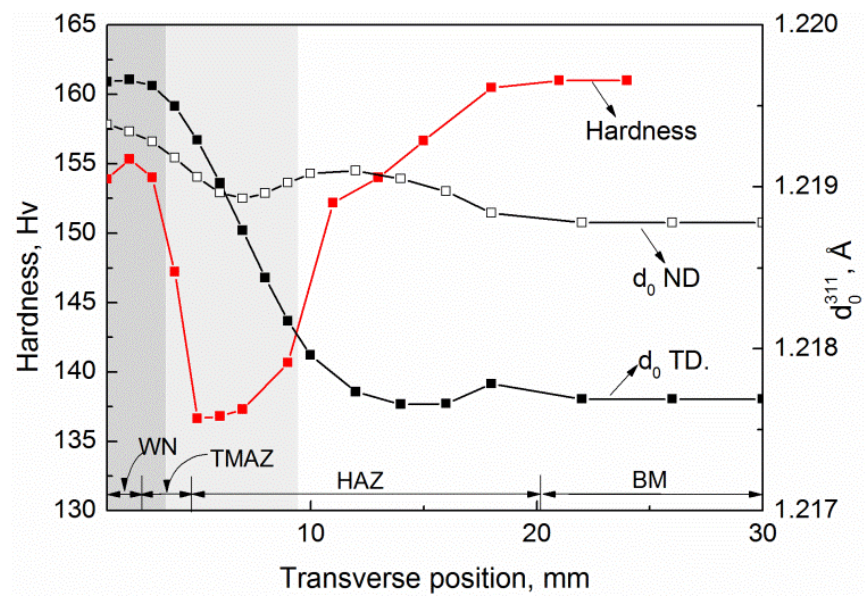

Fig. 7 Variations in hardness (red, left) and $\mathrm{d}_{0}$ (black, right) from weld nugget to base metal of SS1700/200 weld plate.

\subsection{Comparison of the longitudinal residual stress distribution measured by the various techniques}

It is generally good practice to compare stress measurements made by different techniques, especially if one is a destructive mechanical method (CM) and one is non-destructive (ND).

The longitudinal residual stress distributions measured at the mid-thickness by neutron diffraction and the contour method are shown in Fig. 8 and it can be seen that residual stress distributions measured by the three techniques are well matched including the width of tensile stress zone and the higher peak stress value on the AS. The neutron measurements are generally around 40MPa higher in magnitude. This may in part be due to low level plasticity when the EDM wire cuts through the high stresses and partly because of the accumulation of errors in the ND measurements arising from combining strains in 3 directions to calculate the longitudinal stress. However considering the uncertainty in the two measurements (8-20 MPa for neutron diffraction and 15-30 MPa for the contour method [34]) the difference between two methods is acceptable, cross-validating both methods for comparison with the NI method.

It has been proposed by Peel et al. [35] that travel speed is the dominant factor in controlling the residual stress distribution in FSW. As a result the peak longitudinal residual stresses are plotted as a function of travel speed determined by the three techniques to assess the behaviour of neutron imaging at low and high stress level as shown in Fig. 9. It can be seen that NI shows good agreement with the contour method and a higher residual stress level was 


\section{ACCEPTED MANUSCRIPT}

found in the weld with higher travel speed. The difference between the contour method and neutron imaging is less than $30 \mathrm{MPa}$ at both high and low stress level, which suggests that neutron imaging is reliable over a relatively wide residual stress measurement range.

Compared with the conventional neutron diffraction technique, neutron imaging shows advantages in both sample preparation and experimental set up. First, the stress-free sample is simpler to produce since it needs only several parallel cuts to relieve the longitudinal stress as shown in Fig. 1(c) and does not need the precise machining needed in the ND-TD plane for an ND comb sample. Second, during the experiment less time is required for the strain determination since all the positions within the target area are measured in one run, which is more convenient for the case of specimen with complicated geometry. Finally, besides residual stress information, it can be used to investigate the texture evolution at the same time as described in the subsequent section.

Though NI has several benefits, there are still some issues that may limit its application. It is assumed that the strain component along the neutron path within the part is invariant as the measured strain is the averaged value over the whole length [16]. This is a significant limitation because it means the technique is only appropriate for samples with a 2D (extruded) stress field. Furthermore, the sample thickness (neutron path length) needs to be sufficient [14] for the fact that the stress falls to zero at the entrance and exit surfaces not to significant the overall average over the transmitted path. For complex 3D stress fields the technique will not be suitable. Finally, the spatial resolution of this technique is determined by the resolution of the detector - this is currently an advantage because the spatial resolution of state of the art Bragg imaging detectors $(\sim 100 \mu \mathrm{m})$ is better than conventional neutron diffraction gauge volumes (typically $0.25-2 \mathrm{~mm}$ ) [12]. 


\section{ACCEPTED MANUSCRIPT}

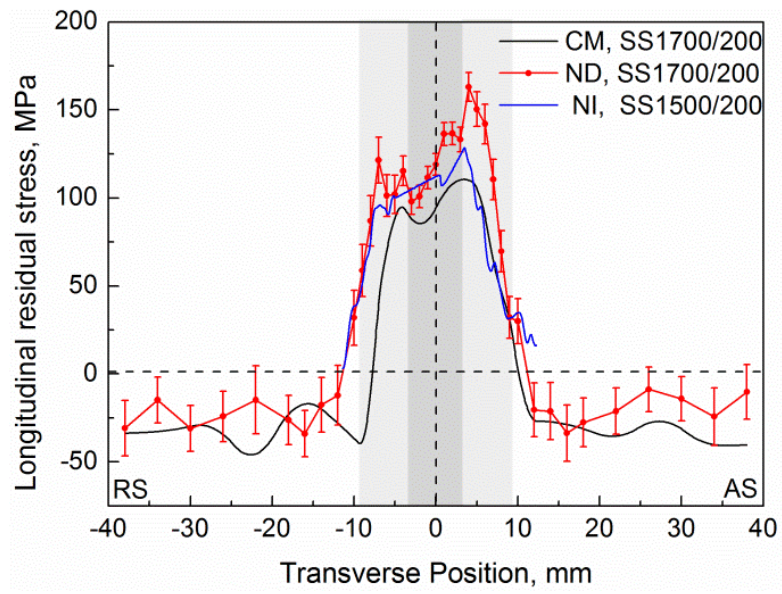

Fig. 8 Longitudinal residual stress distribution in the welds with the identical travel speed of $200 \mathrm{~mm} / \mathrm{min}$ determined by CM (black), ND (red) and NI (blue).

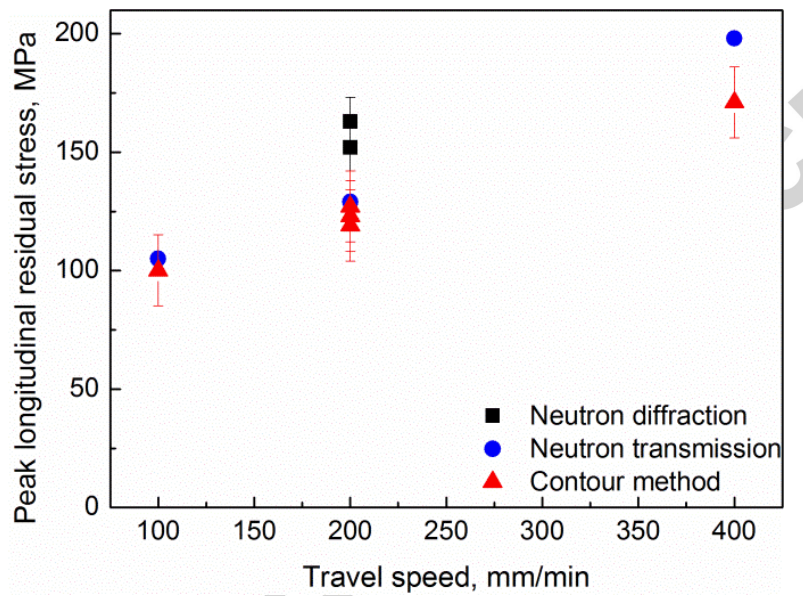

Fig. 9 Peak longitudinal residual stresses determined by neutron diffraction, neutron imaging and contour method as a function of FSW pin travel speed.

\subsection{Determination of texture evolution by neutron imaging}

A representative white-beam transmission image (image integrated over the entire beam spectrum) of the SSFSW weld is shown in Fig. 10. The extent of the beam diffracted out of the transmission image is a function of the texture, leading to the contrast variations in the transmission image [36]. It is apparent that there is a continuous dark band at mid-thickness of the plate in the $\mathrm{BM}$ which indicates the as-supplied plate has a non-uniform texture through the thickness and arises from the rolling of the plate during manufacture. It can be seen that the profile of weld nugget is also visible and its size is comparable with the macrostructure obtained by optical microscope. This is because grains within the WN are randomly orientated and so by contrast with the plate does not show any strong textural preference. 


\section{ACCEPTED MANUSCRIPT}

To verify the assumption that the features in the transmission image arise from the texture variation, the texture of the BM and weld nugget were characterised by EBSD as shown in Fig. 11. It is clear that in the BM there is a significant texture that varies through-thickness due to the severe plastic deformation introduced by the rolling process. A strong texture band was found at the mid-thickness, which matches the features found in the transmission image. Moreover, as indicated by Fig. 11(c), along the LD (111) is the preferred orientation at the mid-thickness. This is consistent with the information extracted from the neutron transmission spectra in Fig. 4. The NI edge is more evident for the (111) plane indicating the (111) plane is the preferred orientation along the direction parallel to the incident beam because there is a sudden change in signal when the (111) planes oriented with the LD can no longer diffract. Towards the WN, features can be discerned near the weld centre in the transmission image that corresponds to changes in texture recorded by EBSD in Fig. 11(b). First, the weld nugget determined by NI and EBSD are consistent in the shape and size. Secondly, the horizontal bands within the weld nugget associated with the material flow induced by the rotating pin is also visible in the EBSD map, and appear more clearly close to the advancing side. Finally, it can be seen from the EBSD map that the TMAZ layer is more distinctive on the advancing side due to the asymmetrical material flow behavior in broad agreement with the sharp boundary contrast and more abrupt transition between weld nugget and HAZ.

While the NT does not give a simple quantitative measure of the texture, it does provide a qualitative indication of textural changes and is more convenient when mapping texture changes over large distances compared to EBSD which would require 440 EBSD maps for 55 hours to cover the complete weld region.

(a)

(b)
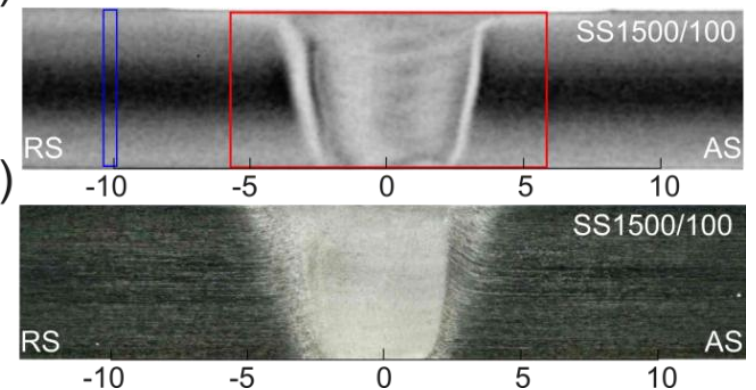

Fig. 10 TD-ND cross-section view of SS1500/100 weld plate characterised as (a) neutron transmission imaging acquired over a narrow range of neutron wavelengths near 111 Bragg edge (4.49-4.63 $\AA$ ) and (b) optical microscopy. 
(a)

(c) 001
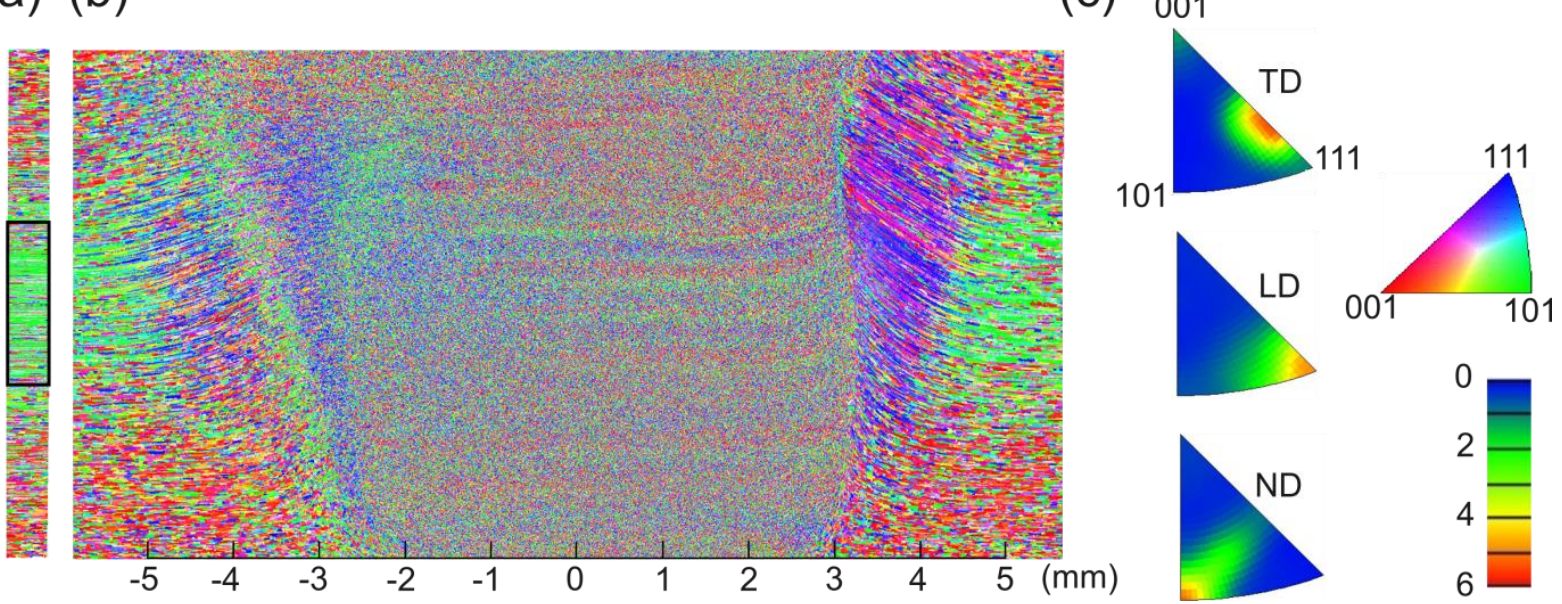

Fig. 11 EBSD IPF colour maps (with respect to ND), (a) taken through the entire thickness of the base metal (from the areas indicated by blue rectangular in Fig. (10), (b) taken through weld centre including weld nugget, TMAZ and HAZ (from the areas addressed by red rectangular in Fig. (10) and (c) Inverse pole Figs summarized from the centre of base metal as addressed in (a).

\section{Conclusions}

In the present study, the residual stress distribution in the SSFSW AA7050 plate was investigated by multiple approaches both destructive and non-destructive, namely contour method, neutron diffraction and neutron imaging. Several conclusions based on the results can be summarized as:

(1) The longitudinal residual stress distributions obtained from all three techniques show good agreement within the uncertainty limits. A high tensile residual stress field $(\sim 170 \mathrm{MPa})$ was found in the WN, being slightly greater on the AS.

(2) Even though the 311 peak was chosen because of its insensitivity to plastic anisotropy. when a single diffraction peak is used to determine the residual stress in the textured material such as the rolled plate studied here, the $\mathrm{d}_{0}$ should be measured and mapped in all three principal directions. This is because the intergranular strain generated during the manufacturing process can lead to a non-uniform variation in the 'stressfree' lattice spacing, where the difference in $\mathrm{d}_{0}$ if unaccounted for could otherwise introduce a strain error of up to $1650 \times 10^{-6}$ which is equivalent to around $120 \mathrm{MPa}$.

(3) For the heat treatable aluminium alloy studied the thermal cycle associated with the SSFSW process has a significant influence on the $\mathrm{d}_{0}$, which is related to the precipitate evolution and thereby the solute concentration. The variation in hardness is 


\section{ACCEPTED MANUSCRIPT}

a good indicator of the sharp change in $\mathrm{d}_{0}$. The stress-free sample must be identical to the weldment, including welding parameters and measurement position.

(4) Neutron imaging is an attractive alternative to the conventional techniques where there is a $2 \mathrm{D}$ (extruded) state of stress as in this case, allowing the simultaneous investigation of residual stress and microstructure in the weldment. Residual stress measurement in the current study shows reliability on the magnitude and size of the tensile residual stress field ranging from 100MPa to $200 \mathrm{MPa}$ in aluminium alloys. The ability to map the residual stress over the entire area exposed to the detector at high spatial resolution $(55 \mu \mathrm{m})$ in one acquisition makes it more competitive when steep gradients in stress are being mapped as here.

(5) The texture variation can be inferred from the neutron transmission contrast enabling a larger region than is feasible by EBSD to be examined.

\section{Acknowledgements}

We are grateful for financial support provided by China Scholarship Council. We would like to thank Mr. David Strong for the production of welds and Mr. Ian Winstanley for performing the contour cuts. We would also like to thank the staff in FRM II Garching, Germany for their kind support of the experiments on their sites. An enthusiastic support of the Noboru neutron beamline scientists Dr. T. Shinohara and Dr. K. Oikawa at the Japan Proton Accelerator Research Complex and the access to the beamline are greatly appreciated. PJW is grateful for a European Research Council for funding COREL-CT under grant No 695638. 


\section{ACCEPTED MANUSCRIPT}

\section{References}

[1] M. Russel, Recent developments in the stationary shoulder FSW of titanium alloys, 7th International Friction Stir Welding Symposium, 2008.

[2] M.M.Z. Ahmed, B.P. Wynne, W.M. Rainforth, P.L. Threadgill, Through-thickness crystallographic texture of stationary shoulder friction stir welded aluminium, Scripta materialia 64(1) (2011) 45-48.

[3] M.-N. Avettand-Fènoël, R. Taillard, Effect of a pre or postweld heat treatment on microstructure and mechanical properties of an AA2050 weld obtained by SSFSW, Materials \& Design 89 (2016) 348-361.

[4] T. Sun, M.J. Roy, D. Strong, P.J. Withers, P.B. Prangnell, Comparison of residual stress distributions in conventional and stationary shoulder high-strength aluminum alloy friction stir welds, Journal of Materials Processing Technology 242 (2017) 92-100.

[5] H. Wu, Y.C. Chen, D. Strong, P.B. Prangnell, Stationary shoulder FSW for joining high strength aluminum alloys, Journal of Materials Processing Technology 221(0) (2015) 187196.

[6] H. Wu, Y.C. Chen, D. Strong, P.B. Prangnell, Systematic Evaluation of the Advantages of Static Shoulder FSW for Joining Aluminium, Materials Science Forum, Trans Tech Publ, 2014, pp. 407-412.

[7] P.J. Withers, Residual stress and its role in failure, Reports on progress in physics 70(12) (2007) 2211.

[8] M.T. Hutchings, P.J. Withers, T.M. Holden, T. Lorentzen, Introduction to the characterization of residual stress by neutron diffraction, CRC press2005.

[9] M.B. Prime, T. Gnäupel-Herold, J.A. Baumann, R.J. Lederich, D.M. Bowden, R.J.

Sebring, Residual stress measurements in a thick, dissimilar aluminum alloy friction stir weld, Acta materialia 54(15) (2006) 4013-4021.

[10] J.R. Santisteban, L. Edwards, M.E. Fitzpatrick, A. Steuwer, P.J. Withers, M.R. Daymond, M.W. Johnson, N. Rhodes, E.M. Schooneveld, Strain imaging by Bragg edge neutron transmission, Nuclear Instruments and Methods in Physics Research Section A: Accelerators, Spectrometers, Detectors and Associated Equipment 481(1) (2002) 765-768. 


\section{ACCEPTED MANUSCRIPT}

[11] J.R. Santisteban, L. Edwards, A. Steuwer, P.J. Withers, Time-of-flight neutron transmission diffraction, Journal of applied crystallography 34(3) (2001) 289-297.

[12] A.S. Tremsin, Y. Gao, L.C. Dial, F. Grazzi, T. Shinohara, Investigation of microstructure in additive manufactured Inconel 625 by spatially resolved neutron transmission spectroscopy, Science and Technology of advanced MaTerialS 17(1) (2016) 324-336.

[13] A.S. Tremsin, W. Kockelmann, A. Paradowska, S.-Y. Zhang, A.M. Korsunsky, T. Shinohara, W.B. Feller, E.H. Lehmann, Investigation of microstructure within metal welds by energy resolved neutron imaging, Journal of Physics: Conference Series, IOP Publishing, 2016, p. 012040.

[14] J. Altenkirch, A. Steuwer, M. Peel, D.G. Richards, P.J. Withers, The effect of tensioning and sectioning on residual stresses in aluminium AA7749 friction stir welds, Materials Science and Engineering: A 488(1) (2008) 16-24.

[15] Z. Feng, X.-L. Wang, S.A. David, P.S. Sklad, Modelling of residual stresses and property distributions in friction stir welds of aluminium alloy 6061-T6, Science and Technology of Welding and Joining 12(4) (2007) 348-356.

[16] A.S. Tremsin, S. Ganguly, S.M. Meco, G.R. Pardal, T. Shinohara, W.B. Feller, Investigation of dissimilar metal welds by energy-resolved neutron imaging, Journal of applied crystallography 49(4) (2016).

[17] A.S. Tremsin, T. Yau, W. Kockelmann, Non - destructive Examination of Loads in Regular and Self - locking Spiralock® Threads through Energy - resolved Neutron Imaging, Strain 52(6) (2016) 548-558.

[18] P.J. Withers, M. Preuss, A. Steuwer, J.W.L. Pang, Methods for obtaining the strain-free lattice parameter when using diffraction to determine residual stress, Journal of applied crystallography 40(5) (2007) 891-904.

[19] C.S. Barrett, T.B. Massalski, Structure of Metals, 3rd, Pergamon Press, 1980.

[20] P.L. Threadgill, A.J. Leonard, H.R. Shercliff, P.J. Withers, Friction stir welding of aluminium alloys, International Materials Reviews 54(2) (2009) 49-93. 


\section{ACCEPTED MANUSCRIPT}

[21] M. Dumont, A. Steuwer, A. Deschamps, M. Peel, P.J. Withers, Microstructure mapping in friction stir welds of 7449 aluminium alloy using SAXS, Acta materialia 54(18) (2006) 4793-4801.

[22] S. Ganguly, L. Edwards, M.E. Fitzpatrick, Problems in using a comb sample as a stressfree reference for the determination of welding residual stress by diffraction, Materials Science and Engineering: A 528(3) (2011) 1226-1232.

[23] M. Hofmann, R. Schneider, G.A. Seidl, J. Rebelo-Kornmeier, R.C. Wimpory, U. Garbe, H.-G. Brokmeier, The new materials science diffractometer STRESS-SPEC at FRM-II, Physica B: Condensed Matter 385 (2006) 1035-1037.

[24] F. Maekawa, K. Oikawa, M. Harada, T. Kai, S. Meigo, Y. Kasugai, M. Ooi, K. Sakai, M. Teshigawara, S. Hasegawa, NOBORU: J-PARC BL10 for facility diagnostics and its possible extension to innovative instruments, Nuclear Instruments and Methods in Physics Research Section A: Accelerators, Spectrometers, Detectors and Associated Equipment 600(1) (2009) 335-337.

[25] A.S. Tremsin, J.V. Vallerga, J.B. McPhate, O.H.W. Siegmund, Optimization of high count rate event counting detector with Microchannel Plates and quad Timepix readout, Nuclear Instruments and Methods in Physics Research Section A: Accelerators, Spectrometers, Detectors and Associated Equipment 787 (2015) 20-25.

[26] D.G. Richards, P.B. Prangnell, P.J. Withers, S.W. Williams, T. Nagy, S. Morgan, Efficacy of active cooling for controlling residual stresses in friction stir welds, Science and Technology of Welding \& Joining 15(2) (2010) 156-165.

[27] D.G. Richards, P.B. Prangnell, S.W. Williams, P.J. Withers, Global mechanical tensioning for the management of residual stresses in welds, Materials Science and Engineering: A 489(1) (2008) 351-362.

[28] M. Wade, A.P. Reynolds, Friction stir weld nugget temperature asymmetry, Science and Technology of Welding and Joining 15(1) (2010) 64-69.

[29] J.W.L. Pang, T. Holden, T. Mason, In situ generation of intergranular strains in an Al7050 alloy, Acta materialia 46(5) (1998) 1503-1518. 


\section{ACCEPTED MANUSCRIPT}

[30] J. Altenkirch, Stress engineering of friction stir welding: measurement and control of welding residual stresses, The University of Manchester, 2009.

[31] M. Dumont, W. Lefebvre, B. Doisneau-Cottignies, A. Deschamps, Characterisation of the composition and volume fraction of $\eta^{\prime}$ and $\eta$ precipitates in an $\mathrm{Al}-\mathrm{Zn}-\mathrm{Mg}$ alloy by a combination of atom probe, small-angle X-ray scattering and transmission electron microscopy, Acta materialia 53(10) (2005) 2881-2892.

[32] G. Sha, A. Cerezo, Early-stage precipitation in Al-Zn-Mg-Cu alloy (7050), Acta materialia 52(15) (2004) 4503-4516.

[33] A. Steuwer, M. Dumont, M. Peel, M. Preuss, P.J. Withers, The variation of the unstrained lattice parameter in an AA7010 friction stir weld, Acta materialia 55(12) (2007) 4111-4120.

[34] F. Martina, M.J. Roy, B.A. Szost, S. Terzi, P.A. Colegrove, S.W. Williams, P.J. Withers, J. Meyer, M. Hofmann, Residual stress of as-deposited and rolled wire+ arc additive manufacturing Ti-6Al-4V components, Materials Science and Technology 32(14) (2016) 1439-1448.

[35] M. Peel, A. Steuwer, M. Preuss, P.J. Withers, Microstructure, mechanical properties and residual stresses as a function of welding speed in aluminium AA5083 friction stir welds, Acta materialia 51(16) (2003) 4791-4801.

[36] W. Kockelmann, G. Frei, E. Lehmann, P. Vontobel, J.R. Santisteban, Energy-selective neutron transmission imaging at a pulsed source, Nuclear Instruments and Methods in Physics Research Section A: Accelerators, Spectrometers, Detectors and Associated Equipment 578(2) (2007) 421-434. 


\section{ACCEPTED MANUSCRIPT}

\section{Figure Captions}

Fig. 1 Schematic of (a) residual stress determined positions by Neutron diffraction and contour method, (b) spatially resolved neutron diffraction measurement positions across the centreline of the weld plate, (c) stress-free reference sample used for the neutron diffraction and neutron imaging.

Fig. 2 Top views of weld plate set-ups for neutron diffraction measurement in (a) TD, (b) ND, (c) LD and (d) neutron imaging measurement in LD. Note that weld plate is not drawn to scale.

Fig. 12 Residual stress distributions determined by neutron diffraction at STRESS-SPEC, FRM II for the stresses components (a) $\sigma_{z z}(x)$, (b) $\sigma_{x x}(x)$ and (c) $\sigma_{y y}(x)$, at mid-thickness of the weld plate for SS1700/200 and SS1300/200.

Fig. 13 Typical neutron transmission spectra measured at different weld zones in SS1500/200.

Fig. 14 Reconstructed longitudinal residual stress contour maps for SSFSWs (the welding parameters are shown on each map) determined by (a) neutron imaging through (i.e. averaged over) $80 \mathrm{~mm}$ length of the weld and (b) from a mid-weld length cross-section by the contour method.

Fig. 15 Stress-free lattice spacing, $d_{0}$ distributions along three principal directions, fitted by $\mathrm{Al}$ (311) peak in the comb sample produced from SS1700/200 weld plate.

Fig. 16 Variations in hardness (red, left) and $\mathrm{d}_{0}$ (black, right) from weld nugget to base metal of SS1700/200 weld plate.

Fig. 17 Longitudinal residual stress distribution in the welds with the identical travel speed of $200 \mathrm{~mm} / \mathrm{min}$ determined by CM (black), ND (red) and NI (blue).

Fig. 18 Peak longitudinal residual stresses determined by neutron diffraction, neutron imaging and contour method as a function of FSW pin travel speed.

Fig. 19 TD-ND cross-section view of SS1500/100 weld plate characterised as (a) neutron transmission imaging acquired over a narrow range of neutron wavelengths near 111 Bragg edge (4.49-4.63 $\AA$ ) and (b) optical microscopy. 


\section{ACCEPTED MANUSCRIPT}

Fig. 20 EBSD IPF colour maps (with respect to ND), (a) taken through the entire thickness of the base metal (from the areas indicated by blue rectangular in Fig. (10), (b) taken through weld centre including weld nugget, TMAZ and HAZ (from the areas addressed by red rectangular in Fig. (10) and (c) Inverse pole Figs summarized from the centre of base metal as addressed in (a).

\section{Table Captions}

Table 1 Matrix of SSFSW parameters used in this paper and applied residual stress measurement techniques for each condition.

\section{Tables}

\begin{tabular}{lccccc}
\hline Designation & $\begin{array}{c}\text { Rotation speed } \\
(\mathrm{rpm})\end{array}$ & $\begin{array}{c}\text { Travel Speed } \\
(\mathrm{mm} / \mathrm{min})\end{array}$ & $\begin{array}{c}\text { Welding } \\
\text { Power }(\mathrm{W})\end{array}$ & $\begin{array}{c}\text { Line } \\
\text { energy }(\mathrm{J} / \mathrm{mm})\end{array}$ & $\begin{array}{c}\text { Measurement } \\
\text { Techniques }\end{array}$ \\
\hline SS1500/100 & 1500 & 100 & 1330 & 796 & CM, NI \\
SS1500/200 & 1500 & 200 & 1550 & 464 & CM, NI \\
SS1500/400 & 1500 & 400 & 2360 & 355 & CM, NI \\
SS1300/200 & 1300 & 200 & 1750 & 526 & CM, ND \\
SS1700/200 & 1700 & 200 & 1610 & 482 & CM, ND \\
\hline
\end{tabular}

Table 1 Matrix of SSFSW parameters used in this paper and applied residual stress measurement techniques for each condition. 